\title{
TRANSFORMASI KEARIFAN LOKAL JAWA DALAM PENDIDIKAN KARAKTER SEKOLAH DASAR
}

\section{TRASFORMATION OF JAVANESE LOCAL WISDOM IN ELEMENTARY SCHOOL CHARACTER EDUCATION}

\author{
Yayuk Hidayah $^{1}$, Yoga Adrian Feriandi ${ }^{2}$, Exwan Adriyan Verry Saputro ${ }^{3}$ \\ ${ }^{1}$ Pendidikan Guru Sekolah Dasar Universitas Ahmad Dahlan Yogyakarta, \\ ${ }^{2}$ Universitas PGRI Madiun, ${ }^{3}$ SMA Muhammadiyah Yogyakarta \\ E-mail: yayuk.hidayah@pgsd.uad.ac.id ${ }^{1}$,yogaadrian@gamil.com² ${ }^{2}$, exwanadriyan@gmail.com
}

\begin{abstract}
Abstrak
Tujuan dari kajian ini adalah untuk mendeskripsikan bagaimana transformasi nilai-nilai lokal Jawa dalam pendidikan karakter di sekolah dasar. Penelitian ini merupakan penelitian studi literatur. Sumber yang digunakan dalam penelitian ini mengacu pada Berg (2009) yaitu 1) artikel ilmiah, disertasi, dan buku, 2) artikel dan essay ilmiah, 3) Ensiklopedi, kamus. 4) artikel jurnal, 5) majalah nasional dan internasional. Penelitian ini dilatar belakangi oleh pentingnya kearifan lokal sebagai salah muatan dalam proses pendidikan. Hasil dari penelitian adalah, terdapat transformasi kearifan lokal Jawa dalam peneguhan pendidikan karakter yaitu tepa slira (toleransi), rukun (cinta damai), rumangsa melu handarbeni, rumangsa wajib hangrungkebi (peduli sosial), memayu hayuning bawana (peduli lingkungan), Aja dumeh (menghargai prestasi, jujur, rendah hati) .
\end{abstract}

Kata Kunci: Pendidikan Karakter, Sekolah Dasar, Kearifan Lokal

\begin{abstract}
The purpose of this study was to describe how the transformation of local Javanese values in character education in elementary schools. This research was a literature study. The sources used in this study refered to Berg (2009), namely 1) scientific articles, dissertations, and books, 2) scientific articles and essays, 3) encyclopedias, dictionaries. 4) Journal article, 5) national and international magazines. This research was in the background of the importance of local wisdom as one of the contents in the Education process. The results of the study were, there was a transformation of Javanese local wisdom in affirming character education namely tepa slira (tolerance), rukun (cinta damai), rumangsa melu handarbeni, rumangsa obligatory hangrungkebi (social care), memayu hayuning bawana (environmental care), Aja dumeh (appreciating achievement, honest, humble)
\end{abstract}

Keywords: Character Education, Elementary School, Local Wisdom

\section{Pendahuluan}

Perubahan, sebagai sebuah proses yang mencakup seluruh aspek dalam kehidupan manusia manjadi hal yang tidak bisa dihindari. Begitupun dalam hal teknologi, prediksi McLuhan pada tahun 1960-an mengenai global village sebagai suatu fenomena dari perkembangan teknologi, kini telah memasuki babaknya (Ngafifi, 2014). Pada kajiannya, mengenai kemajuan teknologi dalam perpektif sosial menemukan setidaknya ada empat (4) temuan, yaitu 1) kemajuan teknologi melahirkan masyarakat digital, 2) adanya perubahan pola manusia menjadi lebih pragmatis, hedonistik, dan sekuler, 3) terdapat dampak positif dan negatif dari perkembangan teknologi, 4) mensinergikan peran keluarga, pendidikan, masyarakat, dan negara sebagai upaya mengurangi dampak negatif dari kemajuan teknologi. 
Menyinggung mengenai globalisasi jika dilihat dari definisi, maka berbagai pendapat mengenai globalisasi akan ditemui. Tomlinson (1999) mendefinisikan globalisasi sebagai suatu pengurangan jarak dalam aktivitas sehari-hari baik secara fisik, maupun secara elektronik. Scholte (2007) mendefinisikan globalisasi dalam istilah yang lebih spesifik, yaitu 1) Internasionalisasi, 2) Liberalisasi, 3) Universalisasi. Dengan demikian dapat disimpulkan bahwa globalisasi merupakan proses sosial yang mencakup ruang dan waktu yang membawa dampak dalam kehidupan manusia. Dampak globalisasi dalam kehidupan setidaknya terdapat empat (4) aspek, yaitu pendidikan, sosial budaya, politik, dan ekonomi.

Sebagai salah satu dampak globalisasi dalam bidang pendidikan, yaitu menjadikan wacana kearifan lokal sebagai salah muatan dalam proses pendidikan menghighlight. Di berbagai negara, globalisasi dalam dunia pendidikan telah menjadi bagian dari perhatian para akademisi. Hanife Akar dalam tulisannya menjabarkan bagaimana negara berkembang menghadapi globalisasi. Hanife Akar memberikan bukti bagaimana globalisasi dalam bidang ekonomi dan politik telah menembus pendidikan tinggi di Turki. Sementara itu, Makule (2010) dalam tesisnya meneliti bagaimana kepemimpinan di sekolah Tanzania telah berubah sebagai salah satu dampak globalisasi. Temuan penelitiannya, mengungkapkan bahwa peran kepemimpinan dalam sekolah telah berubah yakni mulai dari pengawasan, pembelajaran, keterlibatan orang tua, dan kini peran kepemimpinan dalam sekolah mencakup perencanaan, pengembangan, dan peningkatan kualitas sekolah (pengadaan, mengawasi pembangunan sekolah proses belajar mengajar). Studi ini menemukan bahwa dalam globalisasi terdapat peluang dan tantangan.

Dalam konteks Indonesia, Fajarini (2014) memberikan solusi dalam menghadapi globalisasi, yakni perlu ditingkatkannya pengimplementasian Pancasila sebagai ideologi negara Indonesia dalam setiap perumusan kebijakan negara. Selain ideologi Pancasila ia juga menjelaskan bahwa kearifan lokal asli Indonesia juga dapat menjadi senjata dalam menjawab arus zaman. Namun permasalahannya yakni di kalangan pemuda, kearifan lokal saat ini hanya berada dalam tingkat kognitif berupa pengetahuan dan pemahaman semata, tanpa diimbangi penghayatan dan pengalaman. Padahal jika kearifan lokal ini dapat diaplikasikan pada pengetahuan, penghayatan, dan pengamalan maka hal ini dapat menjadi salah satu cara pencegahan karakter negatif. Hal ini dibuktikan oleh kajian yang dilakukan Rasna dan Tantra (2017) bahwa kearifan lokal Bali, yang menganut filosofi Hindu berpotensi untuk pengembangan tema dan sub-tema pendidikan karakter. Dalam penelitian Mujahidin (2016) menghasilkan bahwa kearifan lokal saat ini dikalangan pemuda berada pada tataran pengetahuan dan pemahaman belum pada tataran penghayatan dan pengalaman. Urgensi pelestarian kearifan lokal adalah dalam rangka penyeimbang dengan lingkungan dan sekaligus sebagai upaya pelestarian.

Salah satu cara yang dilakukan untuk mengimplementasikan kearifan lokal dalam pembelajaran di sekolah yakni seperti pengembangan modul pembelajaran berbasis kearifan lokal seperti seni batik yang digunakan sebagai bahan pembelajaran pendidikan karakter siswa (Sugiyo \& Purwastuti, 2017). Selain itu terdapat pula kajian yang dilakukan oleh (Kusniarti, 2015) yang menyimpulkan bahwa teks-teks yang mengandung kearifan lokal berkontribusi dapat memperluas pengetahuan tentang keanekaragaman di Indonesia pada siswa. Sementara itu salah satu temuan penelitian (Agung, 2015) yang bertajuk The Development of Local Wisdom-Based Social Science Learning Model with Bengawan Solo as the Learning Source menghasilkan bahwa, Bengawan Solo dapat digunakan sebagai salah satu sumber belajar kearifan lokal. 
Berangkat dari fakta tersebut, peneliti merasa perlu untuk melakukan kajian mengenai bagaimana transformasi kearifan lokal Jawa dalam pendidikan karakter di sekolah dasar. Berbagai kelebihan yang ada dalam kearifan lokal tersebut mendapat tantangan serius dari perkembangan teknologi, terutama siswa sekolah dasar.

Membelajarkan kearifan lokal bukanlah pekerjaan yang mudah. Terlebih dahulu dipahami bahwa perlu diketahui bahwa karakteristik peserta didik perlu diketahui oleh guru agar dalam penentuan tujuan, metode, dan media pembelajaran dapat tepat (Alfin, 2015). Generasi sekolah dasar merupakan generasi yang berbeda dengan generasi sbelumnya. Berikut penulis sajikan bagaimana timeline generasi agar memudahkan dalam pemahaman bagaiman skema kearifan lokal Jawa dalam pendidikan karakter di sekolah dasar dapat tercapai.

\section{Timeline Generasi}

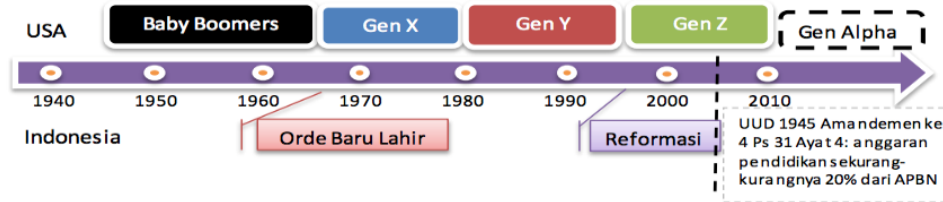

1. Generasi Baby Boomer, lahir 1946-1964,

2. Generasi $X$, lahir 1965-1980,

3. Generasi $Y$, lahir 1981-1994.

4. Generasi Z, lahir 1995-2010, dan

5. Generasi Alpha, lahir 2011-2025.

Sumber : (Wibawanto, 2016)

Dengan data tersebut, maka dapat disimpulkan bahwa untuk mengimplementasikan kearifan lokal dalam generasi ini tentu lebih sulit dibandingkan dengan generasi baby boomers, generasi X, dan generasi Y. Perlu usaha lebih yang tidak hanya sekedar membuat modul-modul pendidikan karakter hasil dari kearifan lokal. Melainkan perlu perubahan bentuk/trasformasi nilai-nilai kearifan lokal ini menjadi sesuatu yang baru dan dapat menyatu dengan teknologi seperti karakteristik yang ada pada generasi yang saat ini sedang berada pada tingkatan sekolah dasar.

Rumusan masalah dari kajian ini adalah bagaimana transformasi kearifan lokal jawa dalam pendidikan karakter sekolah dasar. Adapun urgensi kajian ini dilakukan antara lain. Pertama, kearifan lokal jawa sebagai salah satu warisan leluhur yang patut dilestarikan. Kedua, pendidikan karakter pada sekolah dasar dengan memasukan nilai kearifan lokal merupakan langkah strategis dalam mengenalkan kearifan lokal pada siswa sekolah dasar. Ketiga, sekolah dasar sebagai salah satu jenjang pendidikan yang akan menghantarkan peserta didik ke jenjang selanjutnya.

\section{Metode Penelitian}

Penelitian ini menggunakan metode studi literatur atau library research. Jenis penelitian ini dimulai dengan mengidentifikasi teori dan penelitian sebelumnya yang mempengaruhi (topik dan metodologi) yang relevan (Creswell, 1994; Ridley, 2008). Kemudian dilanjutkan dengan merangkum beberapa tujuan dalam penelitian literature yaitu, (a) pelaporan hasil penelitian kepada pembaca (Fraenkel \& Wallen, 1990) (b) mengembangkan penelitian sebelumnya (Marshall \& Rossman, 1989) (c) kerangka kerja. Sumber yang di gunakan dalam penelitian ini mengacu pada Berg (2009) yaitu 1) artikel ilmiah, disertasi, dan buku, 2) artikel dan essay ilmiah, 3) Ensiklopedi, kamus. 4) artikel jurnal. 5) majalah nasional dan internasional. 


\section{Hasil dan Pembahasan}

Pada sub bab hasil dan pembahasan, peneliti berupaya menyajikan temuan penelitian dalam sub-sub bab. Sebagai upaya dalam sinkronisasi dalam pembahasan, peneliti menyajikan hasil temuan penelitian dibahas secara langsung lalu disimpulkan menjadi temuan penelitian (main finding). Sebagai gambaran dari main finding penelitian peneliti membagi menjadi dua sub bab, yaitu pendidikan karakter di sekolah dasar yang berisi mengenai konsep pendidikan karakter pada sekolah dasar dan transformasi kearifan lokal Jawa dalam pendidikan karakter di sekolah yang berisi temuan lapangan mengenai transformasi kearifan lokal Jawa dalam pendidikan karakter di sekolah dasar.

\subsection{Pendidikan Karakter di Sekolah Dasar}

Salah satu tujuan dari Penerbitan Peratauran Presiden nomor 87 pasal 2 tahun 2017 tentang penguatan pendidikan karakter yakni "membangun dan membekali peserta didik sebagai generasi emas Indonesia tahun 2045 dengan jiwa pancasila dan pendidikan karakter yang baik guna menghadapi dinamika perubahan di masa depan". Dalam tujuan ini, kebermanfaatan di masa depan merupakan poin yang ditekankan. Namun demikian tetap menjadikan Pancasila sebagai ruhnya. Sumber pendidikan karakter di Indonesia, meliputi Pancasila, agama budaya dan tujuan pendidikan nasional. Wiyani (2013) menjelaskan sebagai berikut.

1. Agama, yaitu nilai-nilai pendidikan karakter budaya harus didasarkan pada nilai-nilai kaidah agama;

2. Pancasila, yaitu mempersiapkan peserta didik yang dapat memahami, menghayati, dan mengamalkan nilai-nilai Pancasila;

3. Budaya, yaitu berdasarkan nilai-nilai yang berlaku di masyarakat;

4. Tujuan pendidikan nasional.

Pendidikan karakter di sekolah dasar, harus disesuaikan dengan tahap perkembangannya. Penelitian Muhamad dan Saparahayuningsih (2016) menyebutkan bahwa model pembelajaran ilmiah terpadu mampu menanamkan nilai-nilai sikap dan karakter yang terkandung dalam isi studi sosial kepada siswa. Sementara pada tingkatan sekolah dasar, peserta didik sangat mudah meniru, sehingga dalam penanaman pendidikan karakter, dibutuhkan beberapa strategi. Dalam pendidikan karakter yang terintegrasi dengan satuan pendidikan dalam Puskur (2010) menggambarkan sebagai berikut.

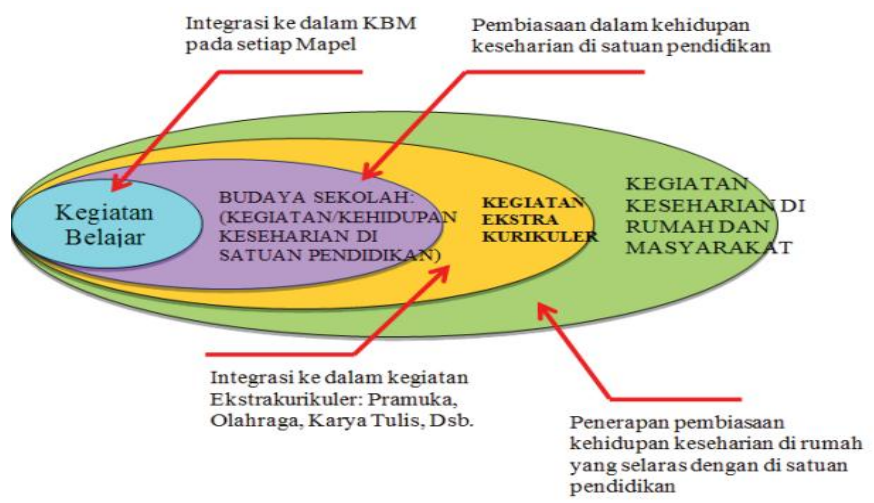

Gambar 1: Desain pendidikan karakter secara mikro di tingkat sekolah, ditjen pendidikan dasar, direkterat pembinaan sekolah dasar, 2011. 
Berdasarkan analisis hasil penelitian ini, maka dapat disimpulkan gambaran model pendidikan karakter di sekolah dasar sebagai berikut:

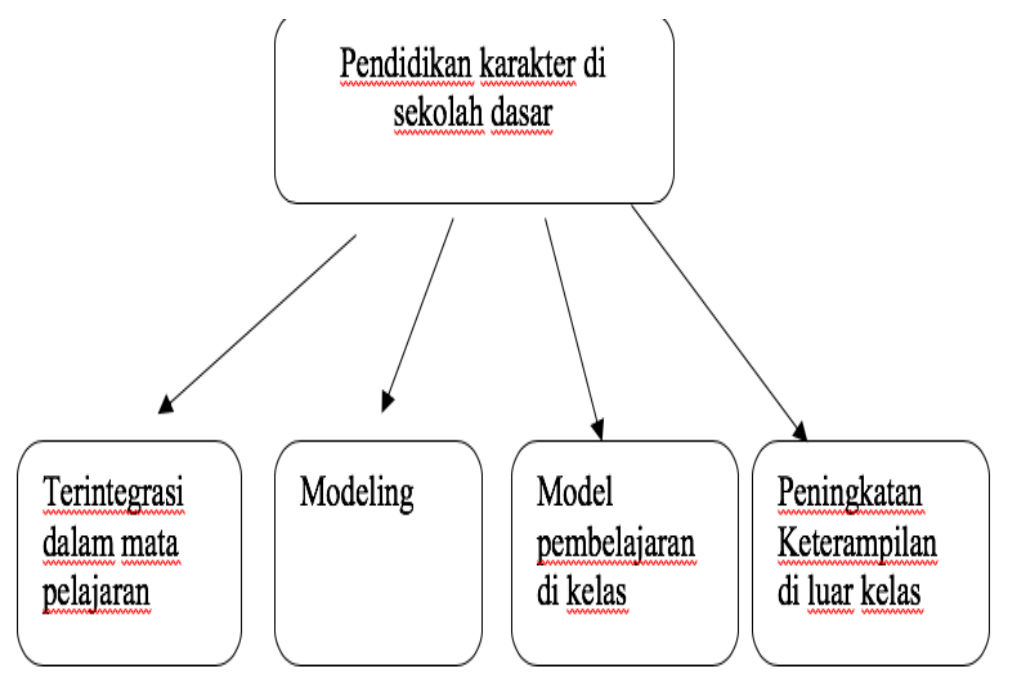

Gambar 2: Gambaran model pendidikan karakter di sekolah dasar

\subsection{Transformasi Kearifan Lokal Jawa dalam Pendidikan Karakter di Sekolah}

Sebagai topik kajian yang luas penulis menyadari keterbatasan temuan pembahasan. Namun demikian dengan keterbatasan kajian, penulis berupaya mengfokuskan temuan dilapangn dengan berdasarkan literatur yang penulis temui. Pada sub bab transformasi kearifan lokal jawa dalam pendidikan karakter di sekolah penulis menyajikan setidaknya ada lima (5) kearifan lokal Jawa yang menurut penulis dapat dimasukan dalam pendidikan karakter di sekolah dasar, yaitu tepa slira (toleransi), rukun (cinta damai), rumangsa melu handarbeni, rumangsa wajib hangrungkebi (peduli sosial), memayu hayuning bawana (peduli lingkungan) aja dumeh (menghargai prestasi, jujur, dan rendah hati).

Kearifan lokal (local wisdom) menjadi hal yang tidak dapat terpisahkan dalam masyarakat. Kearifan lokal eksis dalam rentang waktu yang lama dan tumbuh subur menjadi suatu pandangan yang di dalamnya memuat hal-hal yang baik. Dalam UU No 32 Tahun 2009, kearifan lokal merupakan nilai-nilai luhur yang berlaku di dalam tata kehidupan masyarakat yang bertujuan untuk melindungi sekaligus mengelola lingkungan hidup secara lestari. Sibarani (2018) menjelaskan bahwa kearifan lokal adalah nilai budaya untuk mengelola tatanan sosial dan kehidupan masyarakat, pendapat lainnya, menjelaskan bahwa kearifan lokal adalah pengetahuan dasar yang diperoleh dari hidup yang seimbang dengan alam (Mungmachon, 2012). Dari berbagai definisi ini dapat ditarik kesimpulan bahwa kaerifan lokal merupakan nilai yang eksis di mayarakat dan berasal dari proses yang lama, namun demikian nilai-nilai ini tetap menjadi prinsip dalam kehidupan dalam masyakarat.

Sekolah merupakan organisasi tempat penyelenggaraan pendidikan yang memiliki ritme kerja teratur (Hunt, 1972). Sekolah menggabungkan siswa dan guru dan melakukan kegiatan pendidikan secara terorganisasir dan cara sistematis (Musgrave, 1983). Sekolah berperan dalam fingsi untuk mencapai pendidikan, maka sekolah menjadi pusat pendidikan yang dilembagakan untuk mencapai tujuan belajar (Turkkahraman, 2015). Berdasarkan pendapat mengenai posisi sekolah, maka dalam 
proses pentransferan kearifan lokal, sekolah merupakan sarana yang strategis untuk membelajarkan kearifan lokal ke peserta didik.

Terdapat banyak filosofi, slogan dan keyakinan hidup dalam nilai-nilai kearifan lokal Jawa, yang dapat ditransformasikan dalam penguatan karakter di sekolah. Berdasarkan hasil penelitian Budiyono dan Yoga Ardian Feriandi terdapat beberapa karakter yang dapat digunakan sebagai sumber pendidikan karakter yaitu nastiti, tepa slira, mawas diri, budi luhur, sifat gemi, aja dumeh, ngati-ati sifat gemi jer basuki mawa beya ajining dhiri saka obahing lathi (Budiyono \& Feriandi, 2017). Pelestarian budaya lokal dapat menjembatani dalam perwujudan karakter warga negara yang berkarakter (Ali \& Ruslan, 2018). Kementerian Pendidikan nasional menetapkan beberapa nilai yang harus senantiasa disisipkan dalam proses pembelajaran yakni jujur, religius, toleran, disiplin, keratif, kerja keras, demokrasi, mandiri, semangat kebangsaan, rasa ingin tahu, cinta tanah air, cinta damai, gemar membaca, tanggung jawab, peduli lingkungan, bersahabat, menghargai prestasi, dan peduli sosial.

Sebagai bentuk awal pengenalan terhadap karakter, sekolah memiliki budaya yang secara tidak langsung merupakan usaha penanaman karakter. Budaya tersebut salah satunya adalah pembiasaan salat tepat waktu, pembiasaan ini memiliki misi karakter disiplin yang dapat tumbuh dalam setiap diri peserta didik. Penelitian terdahulu telah menegaskan bahwa pembiasaan (habituation) dapat menjadi proses yang tepat dalam penanaman karakter, dengan membiasakan perilaku positif, sehingga mereka memiliki karakter yang mulia (Lisnawati, 2016). Secara sederhana nilai-nilai kearifan lokal yang menjadi penguatan pendidikan karakter adalah sebagai berikut:

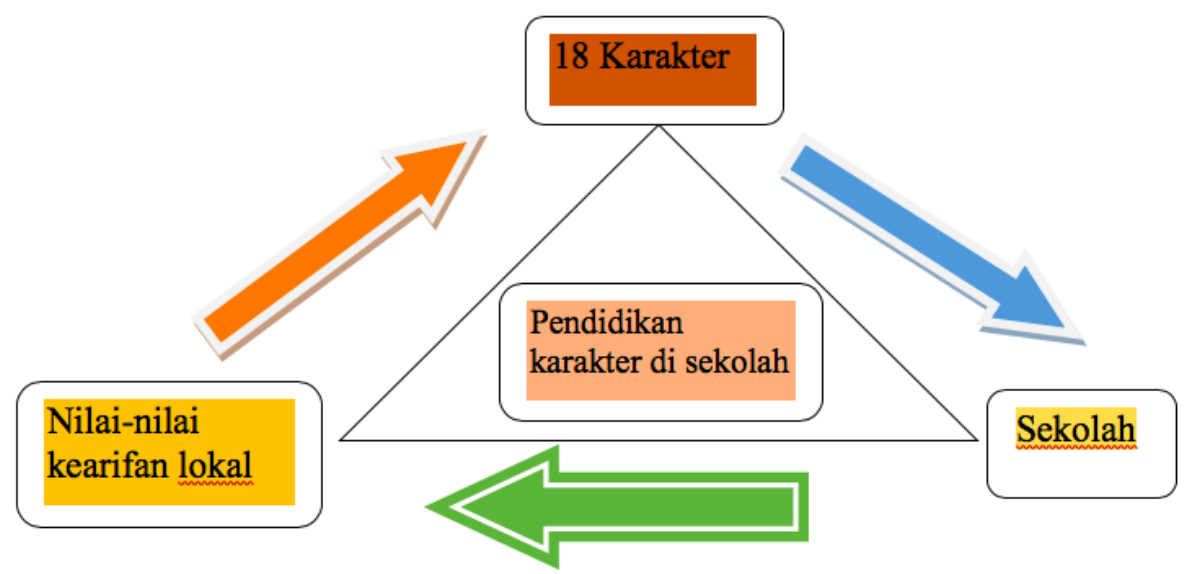

Gambar 3. Transformasi nilai-nilai kearifan lokal yang menjadi penguatan pendidikan karakter di sekolah

Penyampaian etika dalam masyarakat jawa secara umum terdapat dua cara yakni melalui pepali dan pituduh. Pepali merupakan cara penyampaian etika yang berupa larangan akan sesuatu perbuatan yang di anggap sebagai perbuatan yang tidak baik. Sedangkan pituduh dapat dipahami sebagai suatu nasehat untuk berbuat positif. Dalam kearifan lokal Jawa terdapat beberapa makna yang dapat digunakan untuk meneguhkan pendidikan karakter di sekolah dasar, yaitu tepa slira, tepa slira dapat diartikan menghargai pendapat orang lain (Budiyono \& Feriandi, 2017). Tepa slira mengajarkan seseorang untuk mampu melihat dan merasakan dari sudut pandang orang lain. Dengan kata lain dalam tepa slira seseorang di tuntut untuk bersifat tenggang rasa, peduli pada sesama karena sebelum bertindak dia memikirkan bagaimana jika dia di posisi orang 
lain. Lebih lanjut tepa slira juga mengajarkan seseorang untuk selalu berusaha membahagiakan orang lain dan tidak mementingkan diri sendiri (Suratno \& Astiyanto, 2009). Pendidikan karakter memiliki misi untuk mengembangkan, membentuk peserta didik dengan nilai-nilai yang baik sehingga bermanfaat bagi kehidupannya. Dengan demikian maka, dalam penyampaian pendidikan karakter tepa slira dekat kaitannya dengan karakter toleransi, yang merupakan salah satu karakter dari 18 karakter menurut Kementrian Pendidikan Nasional. Dalam masyarakat Indonesia yang majemuk, toleransi manjadi nilai penting bagi anak (Andayani, 2013). Dalam penanaman karakter ke peserta didik, sekolah secara tidak langsung mengemban sebagai instrumen pelestarian nilai-nilai luhur. Pemaknaan tepa slira dalam perwujudan pendidikan karakter berupa toleransi telah diaplikasikan dalam pengajaran karakter. Temuan penelitian ini secara empiris di dukung dengan penelitian relevan, Paiman (2013) menekankan bahwa tepa slira menjadi salah satu komponen yang dapat memunculkan kepekaan sosial sehingga melahirkan toleransi, emosi kerja sama.

Ungkapan jawa selanjutnya adalah rukun yang dekat dengan karakter cinta damai, nilai ini telah ada semenjak dahulu dan berakar dari kebiasan orang jawa yang memiliki kebiasan untuk hidup rukun dan saling hormat menghormati sesama manusia. (Susetyo, Widiyatmadi, \& Sudiantara, 2014) Rukun menjadi konsep harmonis dalam kehidupan bermasyarakat. Dalam KBBI, rukun diartikan tidak bertengkar, baik, bersahabat yang mana nilai ini berkaitan dengan persahabatan dan kekeluargaan. Selanjutnya adalah rumangsa melu handarbeni, rumangsa wajib hangrungkebi, dalam bahasa Indonesia ungkapan ini adalah merasa memiliki, sehingga memiliki kewajiban untuk ikut menjaga dan membela, namun dengan tetap bersikap mawas diri berujung keberanian. Dengan demikian, maka karakter yang dekat dengan ungkapan ini adalah peduli sosial. Peduli sosial muncul dari pemaknaan rumangsa melu handarbeni yaitu merasa ikut memiliki. Secara sederhana kata tersebut bermakna bahwa seseorang hendaklah menyadari bahwa setiap tugas yang diembannya harus dilaksanakan dengan sepenuh hati, dan menjaganya seperti miliknya sendiri (Rosari, 2017). Memayu hayuning bawana dapat diartikan memperindah keindahan dunia, ungkapan ini dekat dengan karakter peduli lingkungan. Dalam ungkapan memayu hayuning bawana dapat dipahami bahwa setiap orang wajib menjaga kelestarian, kedamaian, di sekitarnya agar bisa selamat hidup di dunia (Endraswara, 2012). Falsafah ini bagi orang jawa khususnya di Daerah Istimewa Yogyakarta, menjadi cerminan hubungan antara manusia dan alam yang ada di sekitarnya, karena mereka mengangap bahwa arti hidup adalah memperindah kehidupan. (Khotimah, 2013), Pemaknaan memayu hayuning bawana merupakan konsep tentang hakikat hidup manusia di dunia. Manusia berusaha memperindah dunia dengan keselamatan, kebahagiaan, dan kesejahteraan hidup (Lutfillah, Mangoting, Wijaya, \& Djuharni, 2016). Karakter peduli lingkungan dalam ungkapan ini adalah mengajarkan pada peserta didik berupa menjaga lingkungan sebagai tempat tinggal sehingga tercipta lingkungan yang bersih, nyaman, dan sehat.

Karakter selanjutnya adalah aja dumeh yang dekat dengan karakter menghargai prestasi, rendah hati. Setidaknya ada dua yang didapat dari aja dumeh, pertama sebagai falsafah, yang apabila benar-benar dijalankan, maka kehidupan bermasyarakat akan dapat berjalan dengan baik dan tertib. Kedua, ungkapan ini juga berlaku sebagai nilai etis atau nilai baik dan buruk (Besar, 2010). Aja dumeh mengandung makna rendah hati dan tidak sombong. Dengan demikian maka menghargai prestasi merupakan karakter yang terkandung dalam makna ini. Bahkan ungkapan aja dumeh ini dapat menjadi suatu sumber nilai-nilai moral kewarganegaraan yang berlaku universal tidak hanya berlaku 
bagi orang jawa, melainkan dapat juga berlaku bagi suku lain, hal tersebut dikarenakan dalam ungkapan ini mengandung ajaran untuk menjadi manusia yang selalu bertata krama, amanah, dan dapat dipercaya (Feriandi, 2017). Secara singkat, transformasi kearifan lokal Jawa dalam peneguhan pendidikan karakter dapat peneliti simpulkan sebagai berikut:

Tabel 1. Transformasi Kearifan Lokal Jawa dalam Peneguhan Pendidikan Karakter

\begin{tabular}{ccc}
\hline No & Ungkapan Jawa & Makna dalam Pendidikan Karakter \\
\hline 1 & Tepa Slira & Toleransi \\
\hline 2 & Rukun & Cinta Damai \\
\hline 3 & $\begin{array}{c}\text { rumangsa melu } \\
\text { handarbeni, rumangsa } \\
\text { wajib hangrungkebi }\end{array}$ & peduli social \\
\hline 4 & $\begin{array}{c}\text { memayu hayuning } \\
\text { bawana }\end{array}$ & peduli lingkungan \\
\hline 5 & Aja dumeh & menghargai prestasi , jujur , rendah hati \\
\hline
\end{tabular}

Berdasarkan penelitian sebelumnya, Adapun pendukung temuan penelitian penulis yang dapat memperkuat implementasi dari letak nilai-nilai kearifan lokal dalam pendidikan karakter di sekolah dasar yaitu antara lain kearifan lokal dengan menggunakan gerakan literasi yaitu dengan mengarahan konten materi bacaan dengan nilai-nilai budi pekerti yang didasarkan pada kearifan lokal dengan tetap memperhatikan perkembangan peserta didik (Oktavianti, Zuliana, \& Ratnasari, 2015). Dengan menggunakan penelitian pengembangan temuan penelitian mengenai model materi bahan ajar bahasa Makassar menghasilkan setiap materi terpadu dengan nilai kearifan lokal Makassar (Rabiah, 2013). Penerapan pendidikan kearifan lokal Bali dapat diintegrasikan dalam buku bahan ajar sekolah dasar (Sudiana \& Sudirgayasa, 2015). Pengembangan bahan ajar cerita fiksi berbasis budaya pada sekolah dasar menghasilkan 1) pengembangan bahan ajar sesuai dengan kebutuhan peserta didik, 2) bahan ajar relevan, 3) bahan ajar memenuhi kriteria (Tang, Jufri, \& Sultan, 2015). Melalui uji efektivitas produk dihasilkan bahwa kualitas hasil belajar pada penanaman kaearifan lokal meningkat dengan membandingkan nilai pretest dan posttest (Saputro, Widodo, \& Rusminto, 2014). Berdasarkan dukungan temuan penelitian sebelumnya inilah peneliti berasumsi bahwa kajian pendidikan kearifan lokal dalam sekolah dasar dapat dapat tampak secara jelas diimplementasikan.

\section{Kesimpulan}

Dari analisis data dapat disimpulkan bahwa transformasi kearifan lokal Jawa dalam pendidikan karakter di sekolah dasar dapat dilakukan seiring dengan proses pembelajaran di sekolah dasar. Pendidikan karakter di sekolah dasar merupakan salah satu bentuk alternatif implementasi dari Peraturan Presiden nomor 87 pasal 2 tahun 2017 tentang Penguatan Pendidikan Karakter (PPK). Transformasi kearifan lokal Jawa dalam pendidikan karakter di sekolah tepa slira (toleransi), rukun (cinta damai), rumangsa melu handarbeni, rumangsa wajib hangrungkebi (peduli sosial), memayu hayuning bawana (peduli lingkungan) aja dumeh (menghargai prestasi, jujur, rendah hati). Sebagai prospek pengembangan hasil penelitian, peneliti memberikan rekomendasi kepada peneliti selanjutnya untuk meneliti transformasi nilai-nilai kearifan 
lokal dalam pendidikan karakter yang terdapat pada kearifan lokal lainnya. Hal ini bertujuan selain menggali budaya lokal juga sebagai usaha pelestarian budaya.

\section{Daftar Pustaka}

Agung, L. (2015). The Development of Local Wisdom-Based Social Science Learning Model with Bengawan Solo as the Learning Source. American International Journal of Social Science, 4(4), 51-58. Retrieved from http://www.aijssnet.com/journals/Vol_4_No_4_August_2015/8.pdf

Alfin, J. (2015). Analisis Karakteristik Siswa pada Tingkat Sekolah Dasar. In Prosiding Halaqoh Nasional \& Seminar Internasional Pendidikan Islam (pp. 190-205). Surabaya. Retrieved from http://digilib.uinsby.ac.id/6485/1/15. Analisis Karakteristik Siswa.pdf

Ali, H., \& Ruslan. (2018). Preservation of Local Wisdom Culture (Local Genius) as an Effort to Establish the Character of the Nation. In Proceedings of the Annual Civic Education Conference (ACEC 2018) (Vol. 251, pp. 178-182). Atlantis Press. Retrieved from https://www.atlantis-press.com/proceedings/acec-18/25905935

Andayani, T. R. (2013). Peningkatan Toleransi melalui Budaya Tepa Salira (Pengembangan Model Pendidikan Karakter Berbasis Kearifan Lokal). In Prosiding Seminar Nasional Parenting (pp. 397-406). Retrieved from https://publikasiilmiah.ums.ac.id/bitstream/handle/11617/3957/D2.pdf?sequence $=1$ \&isAllowed $=\mathrm{y}$

Berg, B. L. (2009). Qualitative Research Methods for the Social Sciences (7th Editio). Long Beach.

Besar. (2010). Implementasi Nilai-Nilai Falsafah Ojo Dumeh di Kalangan Mahasiswa Universitas Bina Nusantara. Humaniora, 1(45), 658-667. Retrieved from https://www.researchgate.net/publication/319706143_Implementasi_Nilai-

Nilai_Falsafah_Ojo_Dumeh_Dikalangan_Mahasiswa_Universitas_Bina_Nusantara

Budiyono, \& Feriandi, Y. A. (2017). Menggali Nilai Nilai Kearifan Lokal Budaya Jawa sebagai Sumber Pendidikan Karakter. In Prosiding Seminar Nasional Bimbingan dan Konseling (Vol. 1, pp. 92-103). Retrieved from http://prosiding.unipma.ac.id/index.php/SNBK/article/download/116/115

Creswell, J. W. (1994). Research Design Qualitative and Quantitative Approaches. London.: Sage Publications.

Endraswara, S. (2012). Aspek Budi Luhur dan Memayu Hayuning Bawana dalam Sastra Mistik Penghayat Kepercayaan Kaitannya dengan Pendidikan Karakter. Jurnal Pendidikan Karakter, 2(2), 225-238. Retrieved from https://journal.uny.ac.id/index.php/jpka/article/view/1306

Fajarini, U. (2014). Peranan Kearifan Lokal dalam Pendidikan Karakter. SOSIO DIDAKTIKA: Social Science Education Journal, 1(2), 123-130. Retrieved from http://journal.uinjkt.ac.id/index.php/SOSIO-FITK/article/viewFile/1225/1093

Feriandi, Y. A. (2017). Revitalisasi Moral Kewarganegaraan dalam Ungkapan Jawa Sebagai Sumber Pembentukan Civic Culture dan Politic Culture. Jurnal Civics: Media Kajian Kewarganegaraan, 14(2), 176-182. Retrieved from https://journal.uny.ac.id/index.php/civics/article/download/15323/pdf

Fraenkel, J. R., \& Wallen, N. E. (1990). How to Design and Evaluate Research in Education. Hightstown: McGraw Hill Publishing Co.

Hunt, E. F. (1972). Social Science. New York: The Macmillan Company.

Khotimah, N. (2013). Falsafah Memayu Hayuning Bawana sebagai Potensi Geostrategis 
dalam Undang-Undang No. 13 Tahun 2012 tentang Keistimewaan Daerah Istimewa Yogyakarta terhadap Pengelolaan Sumber Daya Alam. In Prosiding Pertemuan Ilmiah Tahunan XVI Ikatan Geograf Indonesia (pp. 709-716). Retrieved from http://staffnew.uny.ac.id/upload/132319826/penelitian/30-falsafahmemayu-hayuning-bawana-2013.pdf

Kusniarti, T. (2015). Pembelajaran Menulis Naskah Drama dengan Strategi Menulis Terbimbing (SMT) sebagai Upaya Peningkatan Kreativitas Bersastra. KEMBARA: Jurnal Keilmuan Bahasa, Sastra, dan Pengajarannya, 1(1), 108-116. Retrieved from http://ejournal.umm.ac.id/index.php/kembara/article/view/2336

Lisnawati, S. (2016). The Habituation of Behavior as Students' Character Reinforcement in Global Era. Jurnal Pendidikan Islam, 2(3), 413. Retrieved from https://media.neliti.com/media/publications/121610-EN-the-habituation-ofbehavior-as-students.pdf

Lutfillah, N. Q., Mangoting, Y., Wijaya, R. E., \& Djuharni, D. (2016). Konstruksi Tanggung Jawab Auditor dalam Perspektif Memayu Hayuning Bawana. Jurnal Akuntansi Multiparadigma, 7(1), 36-50. Retrieved from https://jamal.ub.ac.id/index.php/jamal/article/view/452/pdf

Makule, A. O. (2010). Globalization and Education: The Changing of School Leadership Role in the Provision of Primary Education In Tanzania. University of Oslo. Retrieved from https://www.duo.uio.no/bitstream/handle/10852/31043/finalxdraft1.pdf?sequence= 2\&isAllowed $=\mathrm{y}$

Marshall, C., \& Rossman, G. B. (1989). Designing Qualitative Research. Newbury Park, CA: SAGE.

Muhamad, B., \& Saparahayuningsih, S. (2016). An Attitude and Character Instructional Development Based on Curriculum 2013 in Elementary School. Creative Education, 7, 269-277. Retrieved from https://file.scirp.org/pdf/CE_2016022414473561.pdf

Mujahidin, A. (2016). Peranan Kearifan Lokal (Local Wisdom) dalam Pengembangan Ekonomi dan Perbankan Syariah di Indonesia. Jurnal Ilmiah Syari 'Ah, 15(2), 154168.

Retrieved from

http://ecampus.iainbatusangkar.ac.id/ojs/index.php/Juris/article/view/496/501

Mungmachon, M. R. (2012). Knowledge and Local Wisdom: Community Treasure. International Journal of Humanities and Social Science, 2(13), 174-181. Retrieved from http://www.ijhssnet.com/journals/Vol_2_No_13_July_2012/18.pdf

Musgrave, P. W. (1983). Sociology of Education. London: Methuen.

Ngafifi, M. (2014). Kemajuan Teknologi dan Pola Hidup Manusia dalam Perspektif Sosial Budaya. Jurnal Pembangunan Pendidikan: Fondasi dan Aplikasi, 2(1), 3347. Retrieved from https://journal.uny.ac.id/index.php/jppfa/article/view/2616/2171

Oktavianti, I., Zuliana, E., \& Ratnasari, Y. (2015). Menggagas Kajian Kearifan Budaya Lokal di Sekolah Dasar melalui Gerakan Literasi Sekolah. In Aktualisasi Kurikulum 2013 di Sekolah Dasar melalui Gerakan Literasi Sekolah untuk Menyiapkan Generasi Unggul dan Berbudi Pekerti (pp. 35-42). Retrieved from https://www.researchgate.net/publication/318760691_MENGGAGAS_KAJIAN_K EARIFAN_BUDAYA_LOKAL_DI_SEKOLAH_DASAR_MELALUI_GERAKA N_LITERASI_SEKOLAH

Paiman. (2013). Kontribusi Pendidikan Jasmani dalam Membentuk Karakter Peserta 
Didik. Jurnal Pendidikan Jasmani Indonesia, 9(2), 134-140. Retrieved from https://journal.uny.ac.id/index.php/jpji/article/download/3016/2509

Puskur. (2010). Pendidikan Budaya dan Karakter Bangsa. Jakarta: PUSKUR.

Rabiah, S. (2013). Pengembangan Materi Ajar Bahasa Makassar Berbasis Nilai-Nilai Karakter dan Kearifan Lokal di Sekolah Dasar Kota Makassar. In Konferensi Internasional Budaya Daerah (KIBD) III yang diselenggarakan oleh Ikatan Dosen Budaya Daerah Indonesia (Ikadbudi) (pp. 1-18). Sukoharjo. Retrieved from https://osf.io/preprints/inarxiv/s8uv5/download

Rasna, I. W., \& Tantra, D. K. (2017). Reconstruction of Local Wisdom for Character Education through the Indonesia Language Learning: An Ethno-pedagogical Methodology. Theory and Practice in Language Studies, 7(12), 1229-1235. Retrieved from http://www.academypublication.com/ojs/index.php/tpls/article/download/tpls0712 $12291235 / 1336$

Ridley, D. (2008). The Literature Review: A Step-by-step Guide for Students (SAGE Study Skills Series). London: SAGE.

Rosari, R. (2017). Hubungan Kepemilikan Psikologikal pada Konteks Budaya Jawa dengan Anteseden dan Konsekuensinya. Jurnal Siasat Bisnis, 21(1), 37-54. Retrieved from https://www.researchgate.net/publication/317113060_Hubungan_kepemilikan_psi kologikal_pada_konteks_budaya_jawa_dengan_anteseden_dan_konsekuensinya

Saputro, E., Widodo, M., \& Rusminto, N. E. (2014). Pengembangan Bahan Ajar Menulis Berbasis Nilai-Nilai Kearifan Lokal. Jurnal J-Simbol (Bahasa, Sastra, Dan Pembelajarannya), 2(1), 1-15. Retrieved from http://jurnal.fkip.unila.ac.id/index.php/BINDO/article/view/7653/4536

Scholte, J. A. (2007). Defining Globalization. Clm.Economía, 10, 1-40. Retrieved from http://www.clmeconomia.jccm.es/pdfclm/scholte.pdf

Sibarani, R. (2018). The Role of Local Wisdom in Developing Friendly City. IOP Conference Series: Earth and Environmental Science, 126, 1-5. Retrieved from https://iopscience.iop.org/article/10.1088/1755-1315/126/1/012094

Sudiana, I. M., \& Sudirgayasa, I. G. (2015). Integrasi Kearifan Lokal Bali dalam Buku Ajar Sekolah Dasar. Jurnal Kajian Bali, 5(1), 181-200. Retrieved from https://ojs.unud.ac.id/index.php/kajianbali/article/download/15732/10515/

Sugiyo, R., \& Purwastuti, L. A. (2017). Local Wisdom-Based Character Education Model in Elementary School in Bantul Yogyakarta Indonesia. Sino-US English Teaching, 14(5), 299-308. Retrieved from https://www.davidpublisher.com/Public/uploads/Contribute/598281065f5e1.pdf

Suratno, P., \& Astiyanto, H. (2009). Gusti Ora Sare: 90 Mutiara Nilai Kearifan Budaya Jawa. Yogyakarta: Adiwacana.

Susetyo, B., Widiyatmadi, E., \& Sudiantara, Y. (2014). Konsep Self dan Penghayatan Self Orang Jawa. Psikodimensia, 13(1), 47-59. Retrieved from http://journal.unika.ac.id/index.php/psi/article/download/277/268

Tang, M. R., Jufri, \& Sultan. (2015). Pengembangan Bahan Ajar Cerita Fiksi Berbasis Wacana Budaya di Sekolah Dasar. Jurnal Pendidikan Dan Pembelajaran (JPP), 22(2), 169-175. Retrieved from http://journal.um.ac.id/index.php/pendidikan-danpembelajaran/article/view/7743

Tomlinson, J. (1999). Globalization and Culture. Cambridge: Polity Press.

Turkkahraman, M. (2015). Education, Teaching and School as A Social Organization. 
Procedia - Social and Behavioral Sciences, 186, 381-387. Retrieved from https://core.ac.uk/download/pdf/81176658.pdf

Wibawanto, H. (2016). Generasi Z dan Pembelajaran di Pendidikan Tinggi. In Mengenal dan Memahami Generasi Z. Haruskah Pendidikan Tinggi Berubah? Retrieved from https://eportfolio4hariwibawanto.files.wordpress.com/2018/11/pembelajaran-bagigenerasi-z.pdf

Wiyani, N. A. (2013). Membumikan Pendidikan Karakter di SD. Yogyakarta: Ar-Ruzz Media. 